\title{
EFFECT OF GREEN SYNTHESIZED SILVER NANOPARTICLES ON CARNOSIC ACID CONTENT AND PHYSIO-BIOCHEMICAL PROPERTIES OF Rosmarinus Officinalis L.
}

\author{
TAYEBEH AZARI NEZHADIAN ${ }^{a}$, PARASTOO MAJIDIAN ${ }^{b}$, MAHYAR GERAMI $^{c^{*}}$, AND MOAZZAMEH RAMEZANI ${ }^{d^{*}}$ \\ ${ }^{a}$ Department of Biotechnology, Sana Institute of Higher Education, Sari, Iran. \\ ${ }^{b}$ Seed and Plant Improvement Research Department, Mazandaran Agricultural and Natural Resources Research and Education Center, \\ Agricultural Research, Education and Extension Organization (AREEO), Sari, Iran. \\ ' Sana Institute of Higher Education, Sari, Iran. \\ ${ }^{d}$ Biology department, Urmia University.
}

\begin{abstract}
In biosynthesis of metal nanoparticles, it is possible to replace the old chemical synthesis methods with new environment-friendly procedures. In this study, AgNP was synthesized using extracts of Rosmarinus officinalis L. leaves, and then its effect on biochemical characters, antioxidant enzymes activity, and finally carnosic acid content was studied with its various concentrations. UV-visible spectroscopy was utilized to identify the formation of synthesized AgNP. Synthesized AgNP was confirmed the absorption maxima at $500 \mathrm{~nm}$ wavelength. Synthesized AgNP were measured using SEM and showed $21 \mathrm{~nm}$ at size and spherical shape. Application of various concentrations of synthesized AgNP demonstrated the concentration dependency so that, in concentration of 40 and $60 \mathrm{mM}$ of synthesized AgNP, dry and fresh weight increased. Application of synthesized AgNP at $40 \mathrm{mM}$ resulted in increase of chlorophyll amount which caused more activity in anti-oxidant enzymes and also biomass accumulation such as soluble carbohydrate and flavonoid. After treatment of synthesized AgNP at $40 \mathrm{mM}$ concentration, HPLC demonstrated an increase in carnosic acid. Here, small nanoparticles revealed increased in secondary metabolites. Synthesized nanoparticles can also be utilized in order to produce natural products and plants with faster growth rates.
\end{abstract}

Keywords: Carnosic acid, Growth factors, Rosmarinus officinalis L, Silver nanoparticles.

\section{INTRODUCTION}

Rosmarinus officinalis L. (R. officinalis) is well-known for having a very high antioxidant activities compared to other herbs [1]. It is popularly utilized as a preserving agent in food stuffs and cosmetic products and it is identified as a source for nutritional supplements $[2,3]$. Compounds that cause this antioxidant activity are known as phenolic diterpenes. Diterpene carnosic acid is the strongest antioxidant agent in rosemary plant. There are also other diterpenes in this plant such as derivative products of carnosic acid which are not effective. Generally, carnosic is converted to carnosol in order to form the phenolic diterpene with $\delta$ - and $\gamma$-lactone functions. In polar and non-polar solvents, carnosic acid will be oxidized into phenolic diterpene under thermal stress $[4,5]$.

Besides antioxidant activity of rosemary extract, its elements are useful for medicinal and physiological applications [6]. For instance, it is reported that small doses of rosemary extract demonstrate the inhibitory effects for human immunodeficiency virus (HIV) infection [7]. Moreover, it is reported that $R$. officinalis has antitumor activities in animal based on in vitro studies. Its main elements, namely rosmarinic acid, ursolic acid, carnosol and carnosic acid are obtained from its activities. It was thought that rosemary's antitumor effect was due to its antioxidant activity, while recently it was reported that there are no connection between rosemary's antioxidant and antitumor effects. However, The U.S. Food and Drug Administration and the European Food and Safety Authority confirmed that certain compositions of rosemary extract are safe for human consumption and are added to foodstuffs as antioxidant. This could be suggested that this agent may potentially be used as an additional method in treatment of cancer [8].

Elicitors are biological and non-biological molecules to which plant receptors on the cytoplasmic membrane react. Thus, plant cells produce a signal that stimulates the gene's expression within the pathway which causes the plant's secondary metabolites to synthesize. The metal nanoparticles application was considered as a potent complement in the area of nanotechnology. Nanotechnology can reduce silver ions to silver nanoparticles with an increase in the surface area of silver [2, 5-8]

In recent years, silver nanomaterial has established considerable attention due to their attractive chemical and electronic properties and their potential applications in improvement of novel technologies. New developments in studies of silver nanomaterials have led to their application including biosensing, diagnostic imaging, cancer diagnosis, therapy, catalysis, food industry, environmental conservation, anti-microbial and cyto-genotoxic properties, nucleic acids-based biosensors, glucose biosensors, fluorescence biosensors, protein-based biosensors, and finally effective drug delivery vehicles [9].
Physical and chemical methods were used to create nanoparticles for years, but due to recent advances, it is now known that microorganisms and biological systems have an important role in production of metallic nanoparticles. Although, chemical reduction of silver salts in the presence of protecting agent is one of the synthesis ways of silver or core shell of silver nanoparticles, applications of nontoxic and renewable sources and environmental friendly solvents have involved great attention due to their improvement in the reduction of environmental risk. Newly, many researchers have been concentrated on NPs synthesis using environmentally polymers as source stabilizing and reducer. Green syntheses of NPs with plant extract are very cost effective, and therefore apply as a valuable and economic alternative way for NPs production in largescale [10]. It is possible to use the materials which are extracted from non-organic substances during the synthesis of AgNP which may be used for source reduction and protection. By combination of present biomolecules such as vitamins, polysaccharides, amino acids, proteins and enzymes, Ag ions were decreased which are environmentally safe $[9,10]$.

The previous research performed by Hebeishb et al [11] demonstrated the synthesis of AgNPs using hydroxypropyl starch as both reducer and stabilizing source. In the research, synthesized AgNPs loaded to cotton fabrics. The Results of antibacterial activity of the cotton fabrics loaded with AgNPs showed that application of AgNPs led to the bacterial reduction which was constantly higher than $95 \%$ compared to the treatment without AgNP.

Another study by Kholood et al [12] showed that AgNP immobilized on silica with s-triazine decorated with 2-aminomethylpyridine (Si-TAMPy) and 8hydroxyqinoloine (Si-TQ) had stability in reaction to oxygen for several months. A potential antibacterial effect of AgNPs on SiTAMPy and Si-TQ was shown against the tested bacterial strains. A study of Hebeisha et al [13] presented a new achievement in synthesis of gold nanoparticles as bimetallic core-shell nanoparticles with AgNP. The innovation of the method is extra maximized by using curdlan (CRD) biopolymer as both reducing and capping agents. On the other hand, microwave helped technology for affecting the AgNP-AuNP-CRD composite with variable concentrations as well as those affected by precursor concentrations.

Other application of nanotechnology is to remove of contaminant from aqueous solution. The combination of adsorption and photocatalysis using Agcolemanite ore waste (COW) is a most effective technique [14]. Determination of quercetin $(\mathrm{QR})$ and morin $(\mathrm{MR})$ has been established on glassy carbon electrode (GCE) modified with nanocomposites of AgNPs-graphene oxide. Thus the advanced technique can be used as an alternative to the chromatographic, spectrophotometric and electroanalytical techniques for determination of QR and MR [15]. 
Fuel explored the synthesis of metallic (AgNP and AuNP) and bimetallic nanoparticle (Ag-AuNP) including L-cysteine as reduced graphene oxide nanocomposite (AgNPs/cis/rGO, AuNPs/cis/rGO, and Ag@Au/cis/rGO) and act as an electrocatalyst for methanol electro-oxidation. Researches demonstrated that the prepared nanocomposites improved electrochemical efficiency for methanol electro-oxidation regarding diffusion efficiency, potential of oxidation, and forward oxidation peak current [16]. A research was performed by John et al [17] showed that AgNP fixed into zeolite $\mathrm{Y}$ and pesticide fenoxycarb decomposed effectively. The photodecomposition of fenoxycarb showed that $\mathrm{AgY}$ act as catalyst.

In the study of Tanju Eren et al [18], it was reported the green synthesis of AgNPs on polyoxometalate (POM) and its application as improved anode material for lithium-ion batteries (LIBs). AgNPs/POM nano composite were measured for charge/discharge specific capacities at different current rates in CR2032 coin-type cells. The prepared AgNPs/POM composite showed a high specific gravimetric capacity and long-term cycle stability.

In a study by Sofian et al [19] showed that Ag nanoclusters loaded in zeolites were prepared and analyzed for catalysts reaction. Ag nanoclusters-zeolites component improved the photodecomposition speed of carbofuran, respectively, and the photodecomposition of carbaryl in the presence of these catalysts indicated room temperature rate that are faster than the photodecomposition of carbaryl in the absence of the silver-loaded zeolite catalysts. Another application of AgNPs was shown that AgNP has effective cyto-genotoxic effects in NT2 (human testicular embryonic carcinoma cells) and primary mouse testicular cells. Researchers discovered that the cyto-genotoxic effects of AgNPs was attributed to a dose-dependent increase in DNA-strand breaks, finally leading to cell death [20].

Due to the high efficiency of plants-mediated biosynthesized nanoparticles in various fields such as medicine, pharmaceuticals and agriculture, the aim of present study was to examine the effects of biosynthesized silver nanoparticle on carnosic acid as well as the effects of biosynthesized AgNP on certain physiobiochemical attributes of $R$. officinalis plant.

\section{MATERIAL AND METHODS}

This study was carried out based on factorial experiment with a totally randomized design using three replications in the research greenhouse of Sana Institute of Higher Education. R. officinalis seedlings were purchased and after planting and ensuring their successful placement, they were sprayed with biosynthesized silver nanoparticles in various concentrations of $0,5,10,20,40$, $60 \mathrm{mM}$ for two times in three weeks.

Lastly, all treated plants were gathered for biochemical and morphological analyses. At the end of the experiment (15 days from planting), growth factors including the fresh and dry weight of root were measured.

\subsection{Preparation of biologically synthesis of AgNP}

$R$. officinalis leaves were gathered, cut and dried for two days at the normal room temperature. Dry leaves were completely washed using distilled water and the aqueous extract was prepared. $20 \mathrm{gr}$ of leaves was added to $90 \mathrm{~mL}$ water and $20 \mathrm{~mL}$ of ethanol. The extract was heated at $70{ }^{\circ} \mathrm{C}$ for 30 minutes.

To achieve a clear solution, the resulted extract was centrifuged and filtered using Whatman 41 filter paper. The remainder was immediately used for the synthesis of AgNP which acted as a reducer and stabilizer agent. $25 \mathrm{~mL}$ of aqueous extract of $R$. officinalis was mixed with $50 \mathrm{~mL}$ of $1 \mathrm{mM} \mathrm{AgNO}_{3}$ using a magnetic stirrer. To ensure complete mixing of the mixture, the mixture was shaken and was then put down at room temperature to settle. The color change to yellow indicated that the silver nanoparticles have formed. The $0.5 \mathrm{ml}$ of sample was diluted using $2.5 \mathrm{ml}$ of Mili-Q water and then its UV spectrum was measured. The same process was performed for each extract.

\subsection{Monitoring and Characteristics of Biosynthesized Silver Nanoparticles}

To synthesize AgNPs, $50 \mathrm{~mL}$ of silver nitrate $(0.001 \mathrm{M})$ was added to an ErlenMeyer flask as a standard solution. Around $0.5 \mathrm{~mL}$ of $R$. officinalis extract was mixed using a magnetic stirrer $(250 \mathrm{rpm})$ at room temperature $\left(25^{\circ} \mathrm{C}\right)$ for 24 hours. After 0,15, 30, 45 min of reduction, synthesis of AgNPs (Ag ions turn into AgNPs) was monitored by UV-VIS spectroscopy.
Green synthesized AgNPs were characterized using SEM, which was also used to morphologically analyze the particles. The aqueous $\mathrm{AgNO}_{3}$ sample was put on the carbon-coated copper grid and was left for an hour at room temperature to allow evaporation of the solvent. Zeiss - EM10C was used to capture the SEM micrograph image on carbon coated copper grids utilizing an accelerating voltage of $80 \mathrm{kV}$. Microscopic pictures were recorded and documented at various levels of magnification.

\subsection{Extraction of Carnosic Acid from Rosemary and Analysis using HPLC}

Crushed rosemary leaves $(10.0 \mathrm{~g})$ were put in ethyl alcohol, water and $100 \mathrm{~mL}$ of ethyl acetate, and water in 4.5:1:4.5 volume ratio. After put at room temperature for 4 full days, we filtered the mixture and analyzed a small amount of the extract analyzed by HPLC using an Aqua C-18-125A $(150 \times 4.0 \mathrm{~mm}, 5$ microns) from Phenomenex (Torrance, CA, USA). The elution was happened gradually starting at $10 \%$ methanol and $90 \%$ water containing $2.5 \%$ acetic acid [21].

\subsection{Biochemical Assay}

\subsubsection{Chlorophyll Measurement}

We used fully developed leaves to measure the amount of chlorophyll [22]. The formulas bellow was used to find the dosage of chlorophyll a and $b$. Hiscox \& Israelstam [23] proved that Arnon's [22] equations for calculation of chlorophyll extracted in $90 \%$ acetone are equal to chlorophyll extracted in DMSO. Here are Arnon's (1949) equations:

Chla $(\mathrm{g} 1-1)=0.0127$ A663 -0.00269 A645

Chlb $(g$ l-1) $=0.0029$ A663 -0.00468 A645

Total Chl $(\mathrm{g} 1-1)=0.0202 \mathrm{~A} 663+0.00802 \mathrm{~A} 645$

\subsubsection{Measurement of Total Carbohydrate}

To calculate carbohydrates content, proteins were detached from the extracts of ethanol by putting at $0^{\circ} \mathrm{C}$ temperature for $15 \mathrm{~min}$. The extracts were concentrated via evaporation of ethanol at $70^{\circ} \mathrm{C}$ under vacuum. To remove chlorophyll, the extracts was mixed with chloroform and then was centrifuged for $5 \mathrm{~min}$.

Total carbohydrates content was calculated using Yemm and Willis enthrone modified method [24]. $1 \mathrm{~mL}$ of the extract was incubated with $5 \mathrm{~mL}$ of enthroning solution $\left(150 \mathrm{mg}\right.$ enthrone in $76 \mathrm{~mL} \mathrm{H}_{2} \mathrm{SO}_{4}$ and $30 \mathrm{~mL} \mathrm{H}_{2} \mathrm{O}_{2}$ ) at $90^{\circ} \mathrm{C}$ temperature for $10 \mathrm{~min}$. The green product was measured to have absorbed at $630 \mathrm{~nm}$.

\subsubsection{Preparation of the Extract for Determination of Flavonoid Content}

The dried plant materials $(10 \mathrm{mg}$ ) were extracted using $75 \mathrm{~mL}$ of ethanol $(95 \%)$ at $4{ }^{\circ} \mathrm{C}$ for $10 \mathrm{~min}$. The solvent was left to evaporate at $40^{\circ} \mathrm{C}$ underneath a reduced pressure chamber. The evaporated extract was conserved for more analyses.

\subsubsection{Assessment of Total Flavonoid Content}

The aluminum chloride calorimetric method was utilized to determine the total flavonoid content and the quercetin was applied to create the standard calibration curve. To prepare the quercetin solution, quercetin $(5.0 \mathrm{mg})$ was dissolved in methanol $(1.0 \mathrm{~mL})$.

Then, standard quercetin solution $(0.6 \mathrm{~mL})$ was mixed with $2 \%$ aluminum chloride $(0.6 \mathrm{~mL})$. The mixture was incubated for $60 \mathrm{~min}$ at room temperature. The absorbance was analyzed at $420 \mathrm{~nm}$ by spectrophotometer. The total flavonoid content was considered as $\mathrm{mg} \mathrm{g}^{-1} \mathrm{FW}$ [25].

\subsubsection{Catalase Activity Analysis}

Aebi's modified method [26] was used to determine the catalase (CAT) enzyme activity. The enzyme activity was measured using a reaction mixture (3 $\mathrm{mL}$ ), which consisted of $2400 \mu \mathrm{l}$ sodium-potassium phosphate buffer $(50 \mathrm{mM})$, $100 \mu \mathrm{L}$ of the enzyme extract and $500 \mu \mathrm{L}$ of hydrogen peroxide $(10 \mathrm{mM})$. Absorption of the reaction mixture was measured at $240 \mathrm{~nm}$ by means of a spectrophotometer (Biochrom WPA Biowave II) with 2 min intervals. 


\subsubsection{Peroxidase Activity Analysis}

By using Chance and Maehly's [27] modified method, the Peroxidase (POX) activity was measured using guaiacol oxidation in the presence of $\mathrm{H}_{2} \mathrm{O}_{2}$. Extraction buffer contained $1700 \mu \mathrm{L}$ of phosphate buffer $(100 \mathrm{mM}), 600 \mu \mathrm{L}$ of Guaiacol $(20 \mathrm{mM})$ and $600 \mu \mathrm{L}$ of the enzyme extract. The reaction commenced after the addition of $100 \mu \mathrm{l}$ of $10 \mathrm{mM}$ hydrogen peroxide to the mixture. Using a spectrophotometer (Biochrom WPA Biowave II) absorbance of mixture was measured at $470 \mathrm{~nm}$.

\subsection{Statistical Analysis}

This experiment was employed a fully factorial randomized design (CRD) and was executed in three biological iterations for each treatment. Variance between various means and its impact was analyzed using one-way ANOVA and least significant difference (LSD) methods in SPSS software (version 23, SPSS, Chicago, IL). The mean comparison was executed using SAS software (SAS Institute, Cary, NC), followed by drawing graphs with MS Office excel.

\section{RESULTS}

3.1 Change of Color in the Mixture after the Emergence of Biosynthesized Nanoparticles

After the production of nanoparticles, the color of the mixture changed from green to dark brown by exposure to sunlight (Figure 1), which indicates the reduction of $\mathrm{AgNO}_{3}$ to AgNPs during the treatment with $R$. officinalis extracts. Enhancement of surface plasmons vibrations caused the change of color to brown. Figure 2 demonstrates the OD value and UV-vis spectra which was periodically recorded from the reaction.

The absorption spectrum of $R$. officinalis extracts ranged from 300 to $700 \mathrm{~nm}$ at different wavelengths and peaked at $500 \mathrm{~nm}$. SEM analysis confirmed the proposal that green syntheses of AgNPs are spherical and revealed that the obtained silver nanoparticles were spherical in shape and averagely measured about $21 \mathrm{~nm}$ (Figure 3).
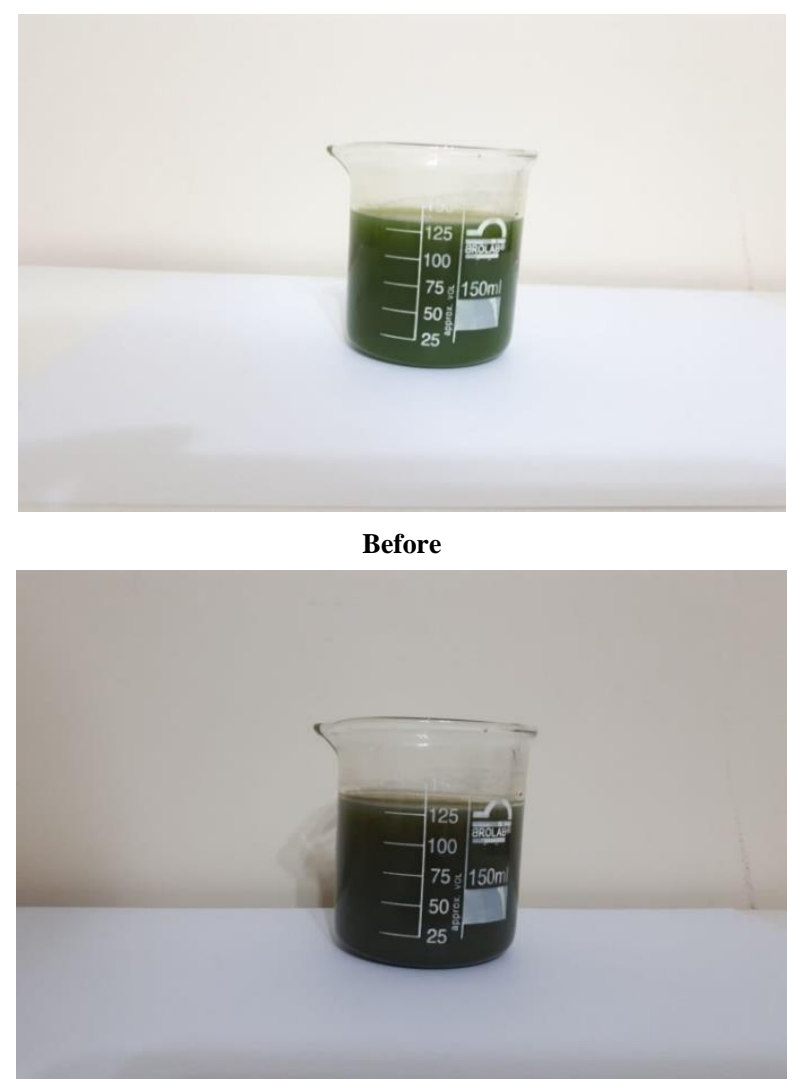

After

Figure 1. Color modification of synthesized silver nanoparticles from R.officinalis extract after $24 \mathrm{~h}$ of synthesizes

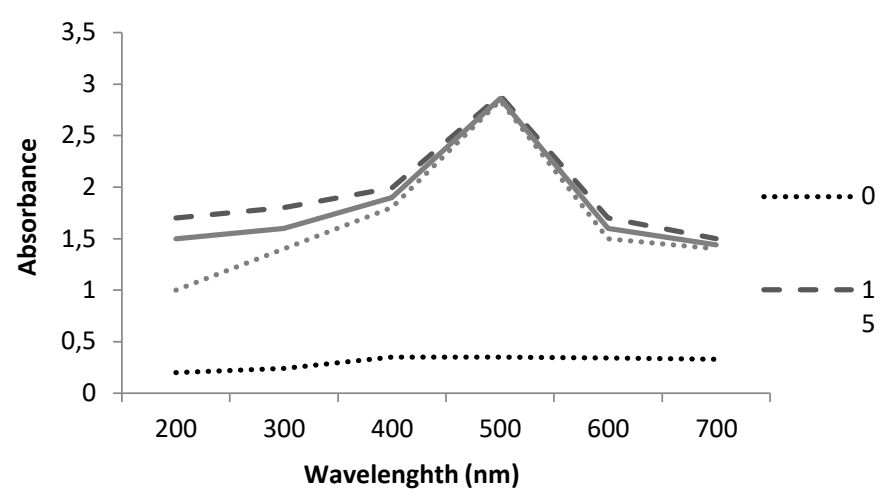

Figure 2. UV-visible spectrum of biosynthesized AgNPs exhibited peak at 435 nm.

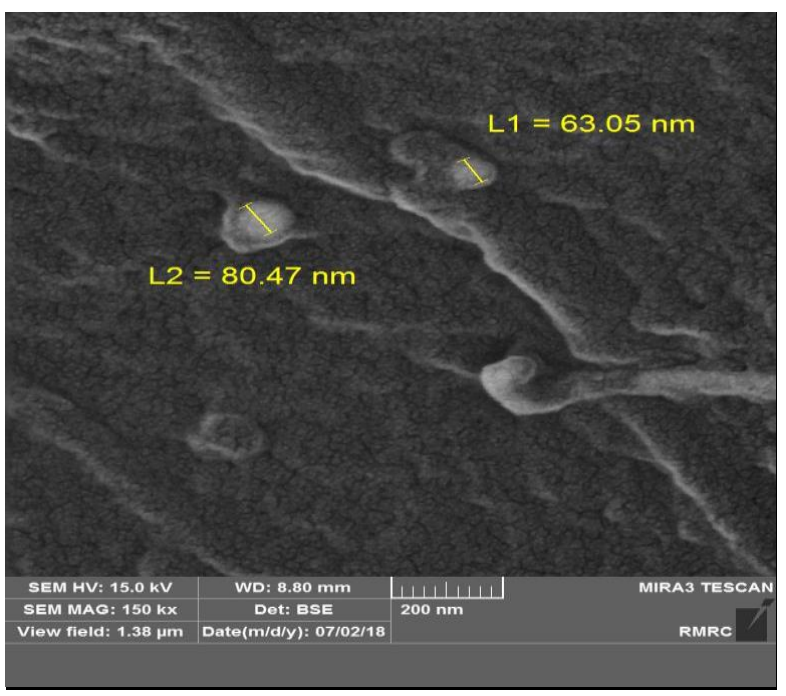

Figure 3. SEM micrograph of synthesized AgNPs from aqueous R.officinalis extract.

\subsection{Results of Morphological Analysis}

Figure 4 demonstrates the effect of various synthesized AgNP concentrations on the fresh and dry weight of the shoot. The results showed a significant increase in the fresh and dry weight of biosynthesized plants leaves treated with AgNP in tandem with the increase in AgNPs. The highest dry and fresh weight was recorded in 40 and $60 \mathrm{mM}$ concentrations of AgNP.

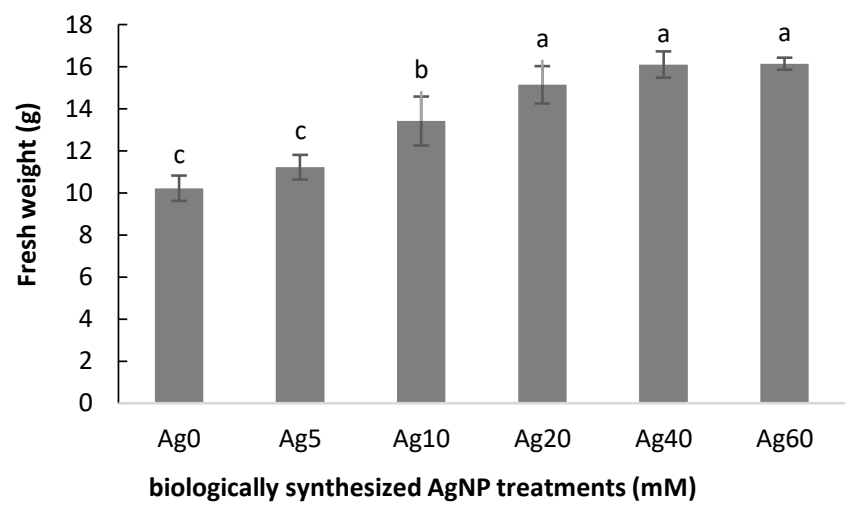

Figure 4. Effect of various concentrations of biosynthesized $\mathrm{AgNP}(\mathrm{Ag} 0, \mathrm{Ag} 5$, $\mathrm{Ag} 10, \mathrm{Ag} 20, \mathrm{Ag} 40, \mathrm{Ag} 60 \mathrm{mM})$ on fresh weight and dry weight of R.officinalis. Data represent the mean $\pm \mathrm{SD}, \mathrm{n}=3$; LSD: least significant difference; significance level: $P<0.05$. In each column, means that have at least one letter in common are not significantly different. 


\subsection{The Result of Biochemical Analysis}

The overall results of this study revealed that treatment with biologically synthesized AgNP led to some biochemical changes in R. officinalis plants. The significant difference was observed between different concentrations of AgNP compared to the control plants $(P \leq 0.05)$.

In case of chlorophyll a (Chl), alteration was just like $\mathrm{Chl} b$, total $\mathrm{Chl}$ and carotenoid. After treatment of plant by synthesized AgNP, a remarkable increase in $\mathrm{Chl} \mathrm{a}, \mathrm{Chl} b$, total $\mathrm{Chl}$ and carotenoid $(41 \%, 41 \%, 38 \%$ and $50 \%)$ was observed at high concentration of $\mathrm{AgNP}(40 \mathrm{mM})$ but followed by a decrease at $60 \mathrm{mM}$ of AgNP (Figure 5 A, B, C, D).

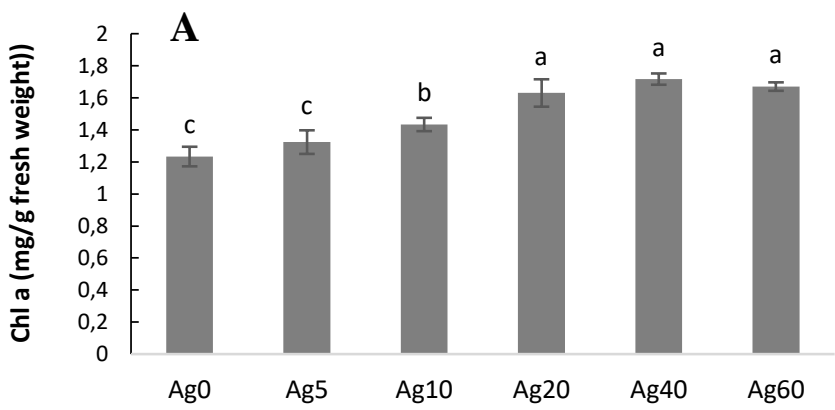

biologically synthesized AgNP treatments (mM)
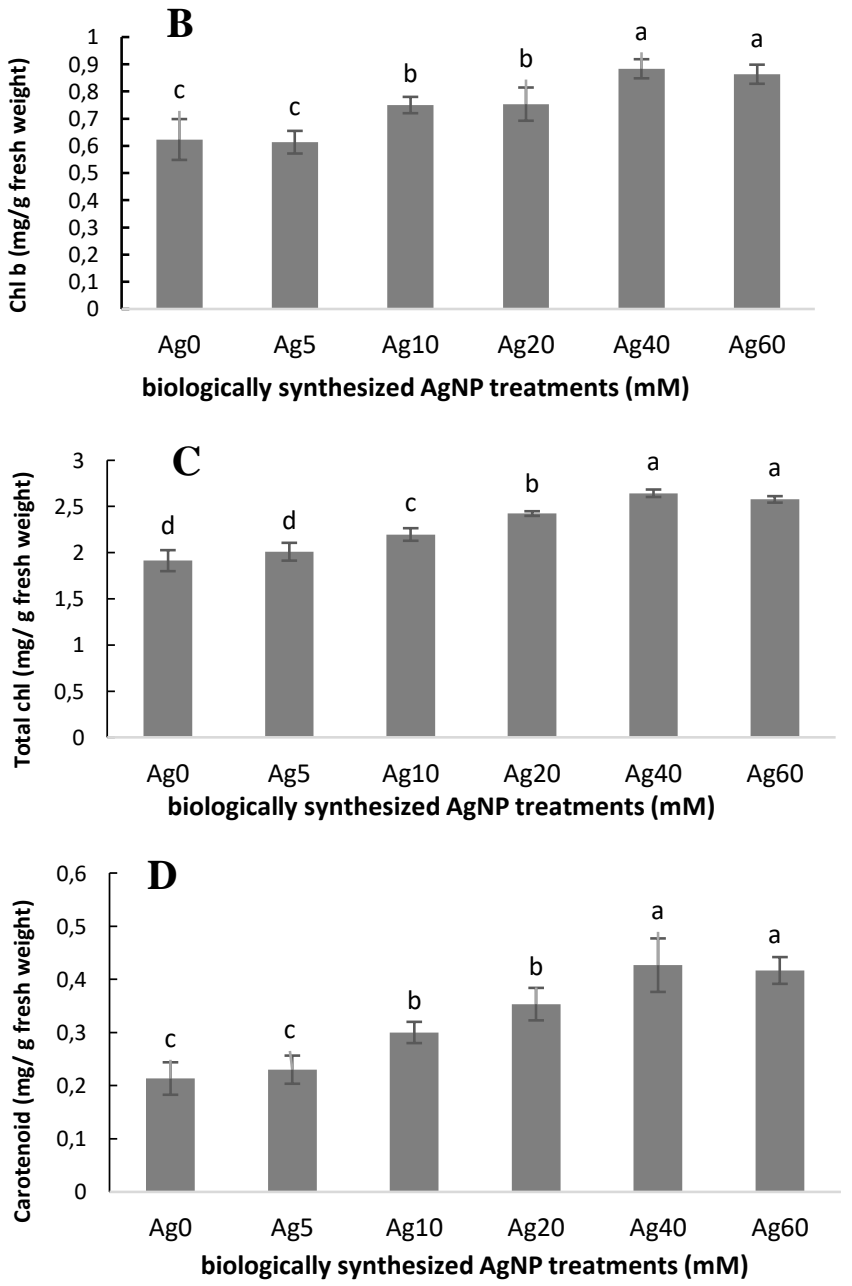

Figure 5. Effect of various concentrations of biosynthesized $\mathrm{AgNP}(\mathrm{Ag} 0, \mathrm{Ag} 5$, Ag10, Ag20, Ag40, Ag60 mM) on A: Chlorophyll a, B: Chlorophyll b, C: Overall chlorophyll and D: Carotenoid in R.officinalis. Data represent the mean $\pm \mathrm{SD}, \mathrm{n}=3$; LSD: least significant difference; significance level: $P<0.05$. In each column, means that have at least one letter in common are not significantly different.
It was achieved the highest overall carbohydrate content $(0.07 \mathrm{mg}$. g-1 FW) at $40 \mathrm{mM}$ concentration of biosynthesized AgNP treated plant before a decrease at $60 \mathrm{mM}$ biosynthesized AgNP. Plants that were treated with $5 \mathrm{mM}$ of biosynthesized AgNP showed the lowest carbohydrate content $(0.04 \mathrm{mg}$. g-1 FW) (Figure 6).

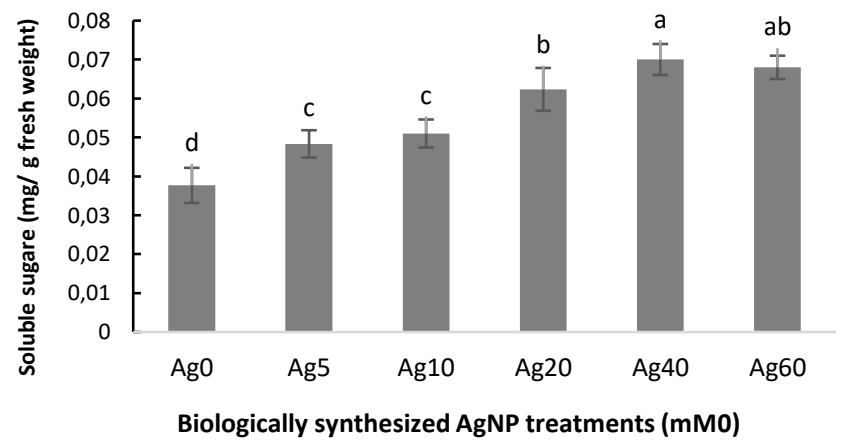

Figure 6. Effect of various concentration of biosynthesized $\mathrm{AgNP}(\mathrm{Ag} 0, \mathrm{Ag} 5$, Ag10, Ag20, Ag40, Ag60 mM) on soluble R. officinalis carbohydrate. Data represent the mean $\pm \mathrm{SD}, \mathrm{n}=3$; LSD: least significant difference; significance level: $P<0.05$. In each column, means that have at least one letter in common are not significantly different.

The highest flavonoids production in biosynthesized AgNP treated plants was observed in 40 and $60 \mathrm{mM}(50.8 \mathrm{mg}$ quercetin/g FW). The lowest flavonoid levels were reported in plants treated with $5 \mathrm{mM}$ biosynthesized $\mathrm{AgNP}(30.2 \mathrm{mg}$ quercetin/g FW) (Figure 7).

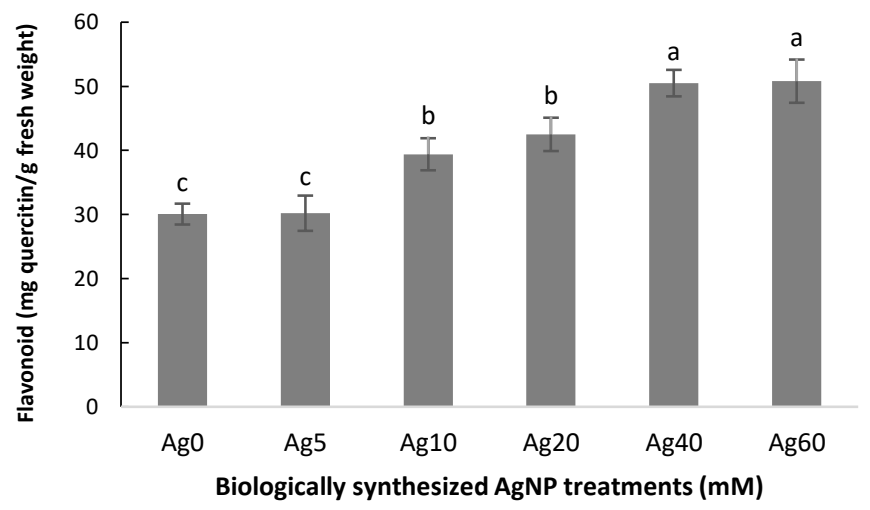

Figure 7. Effect of various concentrations of biosynthesized AgNP (Ag0, Ag5, $\mathrm{Ag} 10, \mathrm{Ag} 40, \mathrm{Ag} 60$ 20, C40, C60 mM) on flavonoid content (mg quercetin / g fresh weight) of R.officinalis. Data represent the mean $\pm \mathrm{SD}, \mathrm{n}=3$; LSD: least significant difference; significance level: $P<0.05$. In each column, means that have at least one letter in common are not significantly different.

\subsection{Effect of Biosynthesized AgNP on Enzymatic Activity}

Among all treatments, plants treated with 40 and $60 \mathrm{mM}$ of biosynthesized AgNP demonstrated the highest CAT enzymatic activity ( $48 \mathrm{U} \mathrm{mg}^{-1}$ proteins), while the lowest CAT activity ( $26 \mathrm{U} \mathrm{mg}^{-1}$ proteins) was recorded in plants treated with $5 \mathrm{mM}$ biosynthesized AgNP (Figure 8).

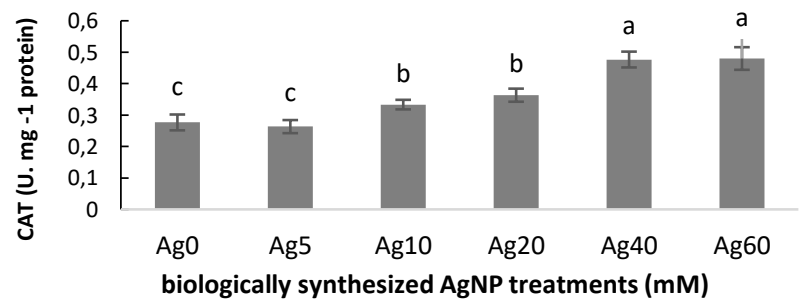

Figure 8. Effect of various concentration of biosynthesized $\mathrm{AgNP}(\mathrm{Ag} 0, \mathrm{Ag} 5$, $\mathrm{Ag} 10, \mathrm{Ag} 40, \mathrm{Ag} 60 \mathrm{mM}$ ) on CAT activity (U mg-1 proteins) of $R$. officinalis. Data represent the mean $\pm \mathrm{SD}, \mathrm{n}=3$; LSD: least significant difference; significance level: $P<0.05$. In each column, means that have at least one letter in common are not significantly different. 
POX activity peaked at $40 \mathrm{mM}$ biosynthesized AgNP concentration (57 $\mathrm{U} \mathrm{mg}^{-1}$ protein) and the lowest activity was recorded at $5 \mathrm{mM}$ biosynthesized AgNP concentration (39 $\mathrm{U} \mathrm{mg}^{-1}$ protein) followed by a decrease in $60 \mathrm{mM}$ nanoparticle concentration (Figure 9).
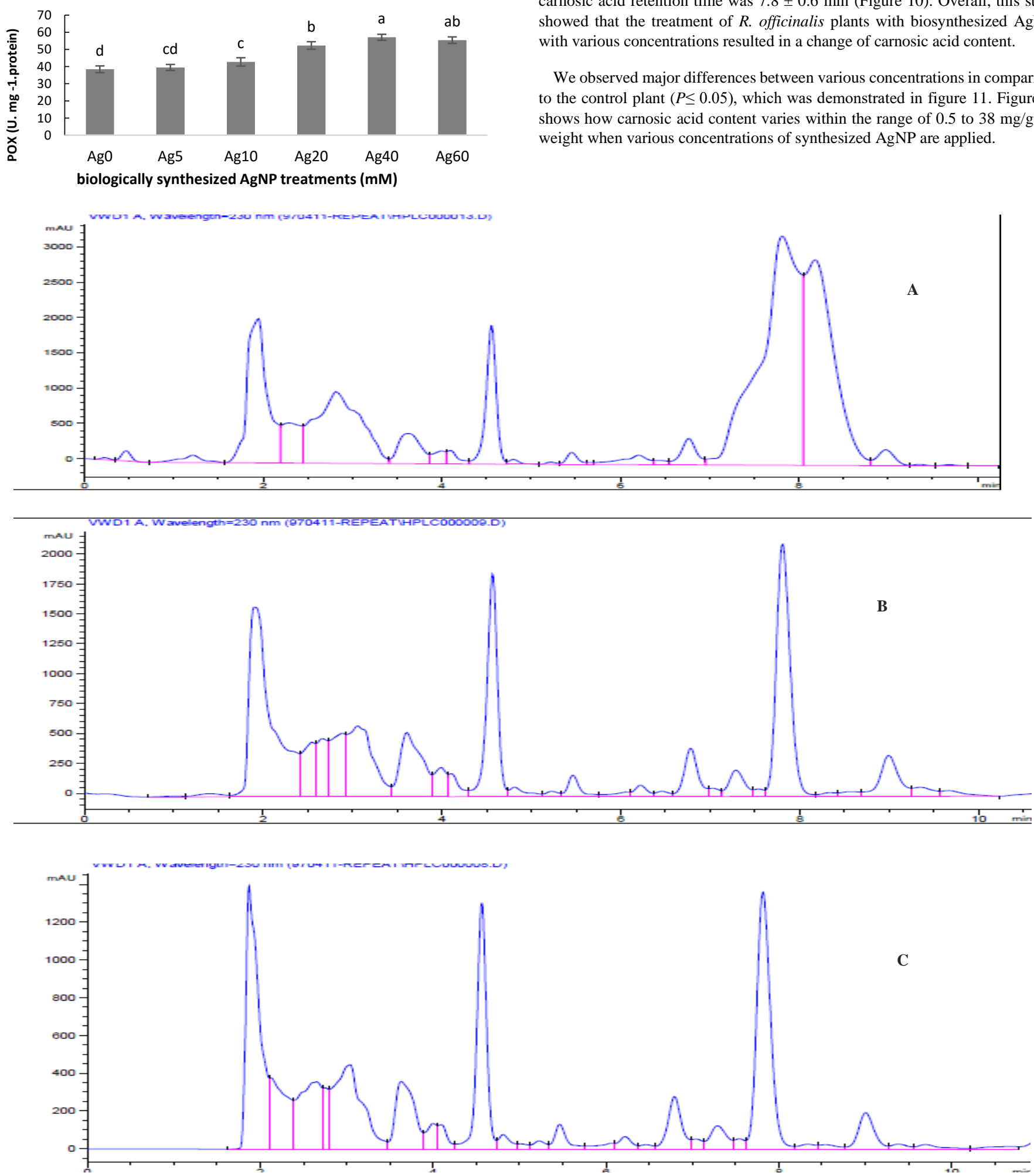

Figure 10: Chromatograms of concomitant treatments of A: syntheiszed AgNP at $40 \mathrm{mM}, \mathbf{B}$ :synthesized AgNP at $20 \mathrm{mM}, \mathbf{C}$ : synthesized AgNP at $10 \mathrm{mM}$ on carnosic acid content of $R$.officinalis.

It was observed the highest amount of carnosic acid content $(34.6 \mathrm{mg} / \mathrm{g}$ dry weight) in plants treated by $40 \mathrm{mM}$ biosynthesized AgNP concentration and the lowest amount was recorded at $5 \mathrm{mM}$ nanoparticle concentration. The carnosic

\subsection{HPLC Analysis of Carnosic Acid Content}

The Performance of HPLC analysis on $R$. officinalis extract revealed major peaks which were identified as carnosic acid based on authentic standards. The carnosic acid retention time was $7.8 \pm 0.6 \mathrm{~min}$ (Figure 10). Overall, this study showed that the treatment of $R$. officinalis plants with biosynthesized AgNPs with various concentrations resulted in a change of carnosic acid content.

We observed major differences between various concentrations in comparison to the control plant $(P \leq 0.05)$, which was demonstrated in figure 11. Figure 11 shows how carnosic acid content varies within the range of 0.5 to $38 \mathrm{mg} / \mathrm{g}$ dry weight when various concentrations of synthesized AgNP are applied. 


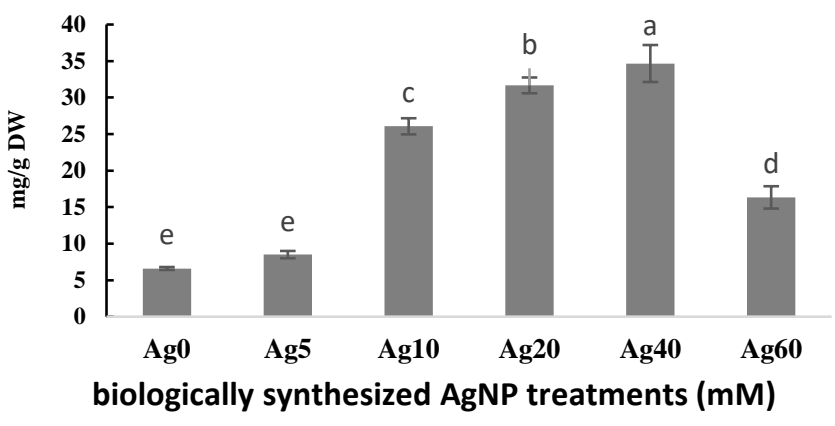

Figure 11: Effect of applying various concentrations of biosynthesized AgNP in (Ag0, Ag5, Ag10, $\mathrm{Ag} 40, \mathrm{Ag} 60 \mathrm{mM}$ ) on carnosic acid content (mg/g dry.w) in tissues of $R$. officinalis leaves. The mean values were the result of three separate experiments. Data represent the mean $\pm \mathrm{SD}, \mathrm{n}=3$; LSD: least significant difference; significance level: $P<0.05$. In each column, means that have at least one letter in common are not significantly different

\section{DISCUSSION}

Medicinal plants are able to benefit from nanoparticles in their pharmacological properties. Synergistic actions of nanoparticles with some biological compounds can be targeted towards sites related to physiological process [28, 29]. Plant has the reducing agent that may contribute to metal ions reduction. These compounds include several flavonoids/flavonoids derivatives, several hydroxycinnamic and one monosaccharide. These components are the substances which are often considered as possible reducing agents in NPs green synthesis [30, 31].

In the present study, the change of color in the mixture from yellow to brown under sunlight exposure indicated the formation of biosynthesized AgNPs as a result of the reduction of $\mathrm{AgNO}_{3}$ after treatment with $R$. officinalis extract (Figure 1). A study by Moteriya et al. [32] exhibited a similar color change in Cassia roxburghii flower extract that signaled the formation of AgNP particles. According to the extracts absorption spectrum, enhancement of surface plasmons vibrations caused the color change to brown within 300 to $700 \mathrm{~nm}$ wavelengths, which peaked at $500 \mathrm{~nm}$. In general, shape, dimensions, arrangement, morphology, and dielectric in the vicinity of the green synthesized AgNPs determine the surface plasmon resonance (SPR) band [33].

Altogether, results of this research demonstrated a positive elicitation effect of synthesized AgNPs on some morphological and biochemical characters in $R$. officinalis. In addition, concentration of elicitor acts an important role in stimulation of physiological process and secondary metabolite biosynthesis in $R$. officinalis. Overall, this study showed a positive elicitation effect on fresh and dry weight and biochemical properties of $R$. officinalis after application of biosynthesized AgNPs. It was suggested that elicitor concentration plays an important role in stimulating the physiological process and biosynthesis of secondary metabolites in $R$. officinalis $[34,35]$.

According to chlorophyll analysis, the content of chlorophyll a, b and total chlorophyll increased after treatment of plants with synthesized AgNP which was similar to previous experiments results reported on the increase of photosynthetic pigments by increment of nanoparticles concentrations [36, 37, 38 and 39].

Treatment of common bean (Phaseolus vulgaris L.) and corn (Zea mays L.) with AgNP resulted in enhanced biochemical properties such as chlorophylls content, carbohydrate and protein $[36,37]$. A research by Tarafdar and Raliya [38] showed that application of AgNP on Cyamopsis tetragonoloba improved the biosynthesis of chlorophyll and protein.

Govorov and Carmeli [39] reported that chemical energy generation in photosynthetic systems was induced by metal nanoparticles. The novel hybrid system formed after AgNPs bound to the chlorophyll in photosynthetic reaction center due to the increased excitation of electrons induced by plasmon resonance and major acceleration of electron-hole separation [39].

Application of nanoparticles increases the gas exchange and chlorophyll fluorescence and also affects other factors such as electron transfer rate, stomatal uptake, transpiration, photosynthesis rate (PSII), phytochemical and effective phytochemical productivity. In one study, $\mathrm{SiO}_{2} \mathrm{NP}$ increased photosynthesis rate and improved the anhydrase carbonic enzyme activity and photosynthetic pigments synthesis [40]. In another study, investigation of $\mathrm{TiO}_{2}$ nanoparticles applications showed improvements in the photosynthesis rate, water conductivity, and transpiration in plant [41]. Also, treatment of plant with nanoparticles exhibited high photosynthesis rate which resulted in increased nutrients and carbohydrate content due to photosynthesis and also larger shoot and heavier fresh and dry weight [42].

Alternatively, AgNP plant treatment increases $\mathrm{Fe}, \mathrm{Ca}$ and water absorption and thus magnifies growth factors [43]. A research by Rezvani et al. [44] showed that AgNP accelerated growth by blocking the ethylene signaling pathway. Furthermore, it was proved that silver ions prevent ethylene from acting by preventing it from connection with some of its receptors in plant cells. The AgNPs could also induce the growth of Brassica juncea seedlings and their antioxidant status followed by increase of fresh weight, root and shoot length [37]. A study by Syu et al. [45] showed promotion effects by AgNPs using various morphology and size in Arabidopsis growth. Arase researchers [46] confirmed that the expression of genes engaged in ABA signaling pathway, IAA biosynthesis, etc. was up-regulated by AgNP treated plants, and afterward an increase in growth was observed. Vannini et al. [47] reported that treatment with silver nanoparticles in Eruca sativa enhanced plant growth and Jacalin-related lectin (JAL) gene expression induction that was associated with the releasing auxin synthesis precursor (nitrile). It could be demonstrated that the pathways interfere in treatment of plant cells with silver nanoparticles affect plant growth ultimately.

Our data showed that application of nanoparticles in $R$. officinalis increased soluble carbohydrate and protein content. Similarly, studies on treatment of $\mathrm{ZnNP}$ on Bacopa monnieri showed the increased protein synthesis as well as carbohydrate induction [48]. Monosaccharides are the reducing sugars that may play a role in the reduction of metal ions $[48,49]$. It is also reported that nanoparticles accelerate growth by increasing soluble carbohydrates [50].

The results of the present research confirmed the nanoparticles ability to decrease plant growth in low concentration, emphasizing the disturbance of cell separation process which causes cell disintegration Chromatin Bridge and stickiness [51, 52]. Furthermore, the negative effects of low concentration of nanoparticle on plant growth was directly affects cell division and indirectly affects $\mathrm{Ag}$ ions release from nanoparticles as well as the production of free radicals in silver nanoparticle plan treatment [53]. Moreover, some nanoparticle properties such as size, shape, plants species, treatment duration, and condition are important factors which can effect on plant's physiological and morphological aspects positively/negatively (toxicity).

The unfavorable size and shape of nanoparticles up-regulated genes expression and protein syntheses such as fructose-1,6 bisphosphate aldolase, protochlorophyllide oxidoreductase, dehydration-responsive (RD22) and celldivision-cycle kinase 2, 9-cis-epoxycarotenoid dioxygenase (NCED3) and induction of gene expression in indole acetic acid protein 8 (IAA8). Also, AgNPs are associated with several cellular events, for instance, silver nanoparticles act as ethylene perception inhibitors and can potentially hinder ethylene biosynthesis by decreasing the expression of ACC synthase 7 and ACC oxidase $2[54,22]$.

AgNPs solubility and ROS production affect their activity. Thus, nanoparticles enter plant cells more easily which results in production of secondary metabolites [28]. El-Temsah and Joner [55] reported that various AgNP concentrations affect the growth in different ways. It was reported by Savithramma et al. [56] that Ag nanoparticles led to rapid growth since new pores penetrated the plant and induced the acceleration of nutrients influx.

Here, the results showed that the biosynthesized AgNP treated plants included increased flavonoids. It was observed that the plant's defensive ability depended greatly on the results of phenylpropanoid pathway products such as flavonoid content which played a major role in elicitor resistivity [57, 58]. AgNP could upregulate main anthocyanin genes and flavonoid biosynthesis pathway in $A$. thaliana [60]. Similarly, the enhancement of flavonoids production was reported by some researchers after treating plants with nanoparticles [61, 62, 63]. A study on maize by Suriyaprabha et al. [64] demonstrated how silver nanoparticles significantly affect phenol and flavonoid content. Lipid peroxidation, CAT activity and oxidative stress $\left(\mathrm{H}_{2} \mathrm{O}_{2}\right.$ production $)$ are the causes of this increase. 
The exposure of Trigonella foenum-graecum L to AgNP treatment increased plant growth and diosgenin concentration [65].

With respect to antioxidant enzyme activity, the CAT and POX activity was incremented bAfter synthesized AgNP treatment. In a study by Krishnaraja et al. [66], low concentration of AgNP resulted in increase of CAT activity and POX activity in Bacopa monnieri. Additionally, a biosynthesis using zinc-silver nanoparticles on Bacopa monnieri showed induction of protein synthesis, and reduction of carbohydrate and phenol content, and decrease of catalyzed (CAT) and peroxidase enzymes activity.

Based on various studies, the general belief is that some initial responses of plants to nanoparticle treatment are enhanced in ROS levels, up-regulation of mitogen-activated protein kinase (MAPK) cascades and cytoplasmic $\mathrm{Ca}^{2+}$ efflux. Plasma membrane-bound receptors recognize AgNPs and then stimulate a $\mathrm{Ca}^{2+}$ burst and induce ROS in A. thaliana. $\mathrm{Ca}^{2+}$ levels and several proteins associated with signaling pathway are up-regulated in plant roots treated with AgNPs [67, $68,69]$. The above mentioned studies exhibited that AgNPs or released ions blocked cell metabolism by joining of $\mathrm{Ca}^{2+}$ receptors, $\mathrm{Ca}^{2+}$ channels and $\mathrm{Ca}^{2+} / \mathrm{Na}^{+}$ ATPases activity. Proteins specific to nanoparticles or calcium-binding proteins mimic $\mathrm{Ca}^{2+}$ in the cytosol [70]. Transcription of secondary metabolism in plants changes after the commencement of MAPK phosphorylation and afterward activation of down-regulation of transcription factors [71, 72]. Activation of additional pathways in the antioxidant system such as enzymatic may lead to a significant decrease in carotenoid acid amount at low to high concentrations. This study demonstrated the possibility of increase in production and accumulation of carotenoid acid by utilizing the biosynthetic cycle.

Based on the HPLC results, carnosic acid rose in the plant treated with $40 \mathrm{mM}$ concentration biosynthesized AgNP, followed by decrease at $60 \mathrm{mM}$. The previous research was done with Majlesi et al. [73] indicated that stevioside and rebadioside content increased after synthesized AgNP treatment on stevia rebaudiosid plant. Different researches showed that metal nanoparticle separately or in the combination with other nanoparticles such as nanocomposites has ability of secondary metabolites induction like rosmarinic acid in Melissa officinalis [74], Saffron in Crocus sativus [75], steviosides and rebaudiosides in Stevia rebaudiana $[76,77,78]$.

Although it was not exactly clear how these elicitors affect the production of carnosic acid, consideration of its antioxidant properties, evidently increasing their production and launching the ROS signaling pathway can be used as an effective ingredient in elicitor-treated rosemary plants, perhaps because of the synthesis induction and activation of genes associated with the defense system, suggesting the increase of secondary metabolite amounts.

Carnosic acid is consumed upon lipids ROS oxidation, and is then oxidized into multiple derivatives, such as carnosol. However, carnosol resisted the oxidation which suggests that carnosic acid may be chemical quencher of ROS. Carnosol's antioxidative function depends on another mechanism which occurs during lipid oxidation. In oxidative situations of ROS generation, lipid peroxidation was inhibited by carnosol which does not occur with carnosic acid. Carnosol and carnosic acid are both able to protect biomembranes and act as membrane lipid protectors in in vivo conditions [79].

\section{CONCLUSION}

In this research, we concluded that nanoscale metals showed dissimilar performances than other treatment. Chemical composition and physical attributes of nanoparticles are very important in their ability to affect plants. Since, silver nanoparticles induced stress after treating plants with biosynthesized AgNPs, the increase of CAT and POX activity was recorded. In the present study, biosynthesized AgNPs demonstrated the increase in production of carnosic acid and total sugar and flavonoids content. Thus, by tagging nanoparticles with secondary metabolites, rosemary offers opportunities in the nanomedicine field. These secondary metabolites can potentially treat common human ailments. These findings may be used in future researches on AgNP phytotoxicity: nanoparticles constructed in particular conditions. So far, there has rarely been any study on the application of nanomaterials on plant tissue, with the aim of their utilization as stress-inducing factors. Results of this study suggests the possibility to use biotechnological processes for production of pure bioactive compounds with antioxidant/reducing properties for green synthesis of AgNPs colloids and different application such as agriculture and pharmaceutical programs.

\section{ACKNOWLEDGEMENTS}

All authors would like to thankful from Sana Institute of Higher Education (Sari-Iran) for providing condition of research experiments.

\section{COMPLIANCE WITH ETHICAL STANDARDS}

Conflict of interest: The authors declare that they have no conflict of interest.

\section{ABBREVIATION}

Silver nanoparticles (AgNPs), Catalase (CAT), Human immunodeficiency virus (HIV), Peroxidase (POX), Photosynthesis rate (PSII), Rosmarinus officinalis L. (R. officinalis).

\section{REFERENCES}

1. J.H. Chipault, G.R. Mizuno, J.M. Hawkins, W.O. Lundberg, J. Food Sci. 17 (1952).

2. F. Aguilar, H. Autrup, S. Barlow, L. Castle, R. Crebelli, W. Dekrant, K.H Engel, N. Gontard, D. Gott, S. Grilli, R. Gurtler, J.C. Larsen, C. Leclerq, J. Leblanc, F.X. Malcata, W. Mennes, M.R. Milana, I. P ratt, I. Rietjens, P. Tobback, F. Toldra, EFSA J 721 (2008).

3. V. Calabrese, G. Scapagnini, C. Catalano, F. Dinotta, D. Geraci, P. Morganti, Int. J. Tissue React 22 (2000)

4. C. Schluttenhofer, and L. Yuan, Plant Physiol 167 (2015).

5. S. Ghahari, S. Ghahari, M. Ramzani, G.A. Nematzadeh, H. Motamedi, Biobased Nanotechnology for Green Applications, (2021).

6. M.S. Bandara, K.K. Tanino, S.N. Acharya, (Editors) Advances in medicinal plant research, in: Acharya SN, Thomas JE (Eds), Rosemary (Rosmarinus officinalis L.): A Medicinal Plant Species. Research Signpost, India (2007).

7. O.I. Aruoma, J.P. Spencer, R. Rossi, R. Aeschbach, A. Khan, N. Mahmood, A. Munoz, A. Murcia, J. Butler, B. Halliwell, Food Chem. Toxicol 34 (1996).

8. S. Birtić, Carnosic acid. Phytochemistry 115 2015).

9. F.M. Amin, C.K. Marsha, M.E. Oussama, M.K. Sofian, Nano Sci. Nanotechnol 4 (2014).

10. S. Iravani, H. Korbekandi, S.V. Mirmohammadi, B. Zolfaghari, Synthesis of silver nanoparticles: chemical, physical and biological methods Res Pharm Sci 9(6) (2014).

11. A. Hebeish, M.E. El-Naggar, M.G. Moustafa, M.A. Ramadanb, S. Salem, M.H. El-Rafie, Highly effective antibacterial textiles containing green synthesized silver nanoparticles, Carbohydrate Polymers 136 (2) (2016).

12. A. Kholood, A. Dahlous, H. Omar, Abd-Elkader, M.G. Moustaf, Fouda, A. Zeid. ALOthmana, Ayman El-Fahama, Journal of the Taiwan Institute of Chemical Engineers 95 (2019)

13. A. Hebeishb, M.E. El-Naggar, M.G. Moustafa, M.A. Foudaa, Ramadan, S Salem. M.H. Al-Deyabc, El-Rafie b, Carbohydrate Polymers 86 (2) (2011).

14. .L.Y. Mehmet, E.N. Tanju, S.W. Atarb, Chemical Engineering Journal 242 (2014).

15. M.L. Yola, Gupta, K. Vinod, T. Eren, A.E. Sen, N. Atar, Electrochimica Acta 120 (2014).

16. A. Necip, E. Tanju, D. Bermali, L.Y. Mehmet, O. C.. Mustafa, Ionics 21 (2015).

17. A.S. K. John, S.T. Ziad, R. Job, N.A. F. Alnaizy, P. Howard, ENV Sci, Pollution Res. 22 (2015).

18. E. Tanju, A. Necip, L.Y. Mehmet, K.M. Hassan, T.Ç. Alper, O. Asim, Ionics 21 (2015).

19. M. Sofian, M.C. Kanan, H.H. Kanan, Res. Chem. Int 32 (2006).

20. .N. Asare, C. Instanes, W. J. Sandberg, M. Refsnes, P. Schwarze, M Kruszewski, and G. Brunborg, Toxicol 291 (2012).

21. N. Okamura, Journal of Chromatography A 679(2) (1994).

22. D.I Arnon, Plant Physiol 24 (1949)

23. J.D. Hiscox, G.F. Can. J. Bot 57(1979).

24. E.W. Yemm, A.J.Willis, Biochem 57 (1954)

25. J. Zhishen, T. Mengcheng, W.u. Jianming, Food. Chem 64 (1999).

26. H. Aebi, H. Bergmeyer, Verlag Chemie, Weinheim. Germany 3 (1983).

27. B. Chance, A.C. Maehly, Methods biochem annals 1 (1954).

28. J.S. Kim, E. Kuk, K.N. Yu, Nanomedicine 3 (2007).

29. D.P. Briskin, Plant Physiol 124 (2000).

30. A. Pancek, L. Kvtek, R. Prucek, M. Kolr, R. Vecerov, N. Pizorov, V.K Sharma, T. Nevecn, R. Zboril, J. Phys. Chem. B 110 (33) (2006).

31. Y. Zhou, W. Lin, J. Huang, W. Wang, Y. Gao, L. Lin, Q. Li, L. Lin, M. Du, Nanoscale Res Lett 5 (2010).

32. P. Moteriya, H. Padalia, R. Jadeja, S. Chanda, Review: screening of silver nanoparticle synthetic efficacy of some medicinal plants of Saurashtra region. 
In: Gupta VK, editor. Natural products: research review, vol. 3. New Delhi: Daya Publishing House (2016).

33. D. Lim, J.Y. Roh, H.J. Eom, J.Y. Choi, J. Hyun, and J. Choi, Environ. Toxicol. Chem 31 (2012).

34. H. Qian, X. Peng, X. Han, J. Ren, Fu.Z. Sun, J. Environ. Sci 25 (2013).

35. F. Perreault, M. Samadani, D. Dewez, Nanotoxicol 8 (2014).

36. H.M.H. Salama, Int. Res. J. Biotechnol 3 (2012).

37. P. Sharma, D. Sharma, M.G.H. Bhatt, P.P. Zaidi, P.K. Saradhi, S. Khanna, Appl. Biochem. Biotechnol 167 (2012).

38. J.C. Tarafdar, and R. Raliya, Agri Res 2 (2013).

39. A.O. Govorov, I. Carmeli, Nano Lett 7(3) (2007).

40. M.H. Siddiqui, M.H. Al-Whaibi, M. Faisal, A.A. Al Sahli, Environ. Toxicol. Chem 33 (2014).

41. M. Qi, Y. Liu, T. Li, Biological Trace Element Research 156 (2013).

42. M. Kalteh, Z.T. Alipour, S. Ashraf, M.M. Aliabadi, A.F. Nosratabadi, J. Chem. Health Risks 4 (2014).

43. D.K. Tiwari, N. Dasgupta-Schubert, L.M. Villaseñor-Cendejas, J. Villegas, L. Carreto Montoya, and S.E. Borjas-García, Applied Nanoscience 4 (2014).

44. N. Rezvani, A. Sorooshzadeh, N. Farhadi, Int. J. Biol. Biomol. Agric. Food. Biotechnol. Eng 6 (2012).

45. Y. Syu, J.H. Hung, J.C. Chen, Plant Physiol. Biochem 83 (2014).

46. F. Arase, H. Arase, M. Nishitani, N. Egusa, S. Nishimoto, N. Sakurai, H. Sakamoto, I. Kaminaka, PLoS ONE 7 (2012).

47. C. Vannini, G. Vannini, E. Domingo, B. Onelli, M. Prinsi, L. Marsoni, M. Espen, Bracale. PLoS ONE 8 (2013) e68752.

48. C. Krishnaraj, E.G. Jagan, R. Ramachandran, S.M. Abirami, N. Mohan, P.T. Kalaichelvan, Plant growth metabolism, Process Biochemistry 47 (2012).

49. J. Zhao, K. Sakai, Journal of Experimental Botany 54(383) (2003).

50. Xu. Sh, T. Lou, N. Zhao, Y. Gao, L. Dong, D. Jiang, W. Shen, L. Huang, and R.Wang, Acta Physiol. Plant 33 (2011).

51. M. Kumari, A. Mukherjee, N, Sci. Total Environ 407(2009).

52. P.V. Asharani, Y.L. Wu, Z. Gong, S.Valiyaveettil, Nanotechnology 19 ( 2008).

53. A. Kumar, V. Nirmala, Indian J Pharmaceut Sci 66(5) (2004).

54. E. Navarro, A. Baun, R. Behra, Ecotoxicol 17 (2008).

55. Y.S. El-Temsah, E.J. Joner, Toxicol 27(2012).

56. N. Savithramma, S. Ankanna, G. Bhumi, Nano Vision 2 (2012).

57. M. Ramezani, F. Ramezani, F. Rahmani, A. Dehestani, sci horti j 234 (2017).
58. M. Ramezani, F. Rahmani, A. Dehestani, sci horti j 225 (2017).

59. F. Daayf, M. Ongena, R. Boulanger, I.E. Hadrami, and R.R. Belanger, J. Chem. Ecol 26 (2000).

60. S. Garcia-Sanchez, I. Bernales, and S. Cristobal, BMC Genomics 16 (2015).

61. M. Comotto, A.A. Casazza, B. Aliakbarian, V. Caratto, M. Ferretti, and P. Perego, Sci. World J 9 (2014).

62. M. Ghorbanpour, and J.Hadian, Carbon 94 (2015).

63. K. Vecerova, Z. Vecera, B. Docekal, M. Oravec, A. Pompeiano, J. Tríska, Pollut 218 (2016).

64. R. Suriyaprabha, G. Karunakaran, R. Yuvakkumar, V. Rajendran, N. Kannan, Curr Nanosci 8(6) (2005).

65. B. Jasim, R. Thomas, J. Mathew, E.K. Radhakrishnan, Saudi Pharm. J 25 (2017).

66. C. Krishnaraj, E.G. Jagan, R. Ramachandran, S.M. Abirami, N. Mohan, P.T. Kalaichelvan, Plant growth metabolism, Process Biochemistry 47 (2012).

67. M. Ramezani, F. Ramezani, M. Gerami, Nanoparticles in Pest Incidences and Plant Disease Control: Nanotechnology for Agriculture: Crop Production \& Protection, (2019).

68. A. Sosan, D. Svistunenko, D. Straltsova, K. Tsiurkina, I. Smolich, T. Lawson, Plant J 85 (2016).

69. M.N. Kha, M. Mobin, Z.K. Abbas, K.A. Almutairi, and Z.H. Siddiqui, Plant Physiol. Biochem 110 (2017).

70. C. Schluttenhofer, and L. Yuan, Plant Physiol 167 (2015)

71. U.J. Phukan, G.S. Jeena, and R.K. Shukla, Front. Plant Sci 7 (2016).

72. Lim, D., Roh, J.Y, Eom, H.J., Choi, J.Y., Hyun, J., and Choi, J. Environ. Toxicol. Chem 31 (2012).

73.Z. Majlesi, M. Ramezani, M. Gerami, Pharmaceutical and Biomedical Research 4(1) (2018).

74. R.K Soraki, M Gerami, M Ramezani, BMC Plant Biology 21 (2021).

75. L. Badihi, M. Gerami, D. Akbarinodeh, M. Shokrzadeh, M. Ramezani, Physiology and Molecular Biology of Plants 1-15 (2021).

76. S. Nokandeh, M. Ramezani, M. Gerami, Journal of Plant Biochemistry and Biotechnology 1-7(2020).

77. M. Ramezani, S. Asghari, M. Gerami, F. Ramezani, M.K. Abdolmaleki, Sugar Tech 1-10 (2019).

78. M. Ramezani, M. Gerami, Z. Majlesi, plant physiology reports, (2019).

79. E.N. Frankel, Journal of Agricultural and Food Chemistry 44(1) (1996). 